\title{
Collections Care Challenges and Innovations for Ephemeral Altar Assemblages
}

Défis et innovations du soin des collections pour les compositions d'autel

éphémères

\section{Caitlin Spangler-Bickell}

\section{(2) OpenEdition}

\section{Journals}

Electronic version

URL: http://journals.openedition.org/iss/1814

DOI: $10.4000 /$ iss. 1814

ISSN: 2306-4161

\section{Publisher}

ICOM - International Council of Museums

\section{Printed version}

Date of publication: 12 October 2019

Number of pages: 171-190

ISBN: 978-92-9012-467-2

ISSN: 2309-1290

\section{Electronic reference}

Caitlin Spangler-Bickell, « Collections Care Challenges and Innovations for Ephemeral Altar

Assemblages ", ICOFOM Study Series [Online], 47(1-2) | 2019, Online since 12 October 2019, connection on 24 October 2019. URL : http://journals.openedition.org/iss/1814 ; DOI : 10.4000/iss.1814 


\section{Collections Care Challenges and Innovations for Ephemeral Altar Assemblages}

\section{Caitlin Spangler-Bickell \\ Maastricht University, the Netherlands / Museo delle Culture Milan, Italy}

"Both the museum as an archive and the museum's archive [...] shape the identity of an artwork in the museum's custody by determining what is - and can be - known about it" Hanna Hölling, 20I7, p. I43

\section{ABSTRACT}

This contribution evaluates the installation of (inter)active altar assemblages in museums from the underexamined perspective of collections care practice. Based on ethnographic research at the Fowler Museum at UCLA - which has been exhibiting altars for over two decades - this article investigates the details of constructing, maintaining, documenting and conserving altars. Firstly, it examines the Fouler's innovative use of registration categories to contend with the fluid identities, status, and functions of individual altar components referred to as "TRs", "Props", and "Offerings". Secondly, it offers a comparative analysis of 
curatorial and conservation documentation for three entire altars - one of which was also a contemporary artwork - in the 2008 exhibition Mami Wata: Arts for Water Spirits in Africa and Its Diasporas. This study reveals challenges of exhibiting ephemeral altar assemblages, provides examples of museological innovation to meet those challenges, and highlights the vulnerabilities of such innovations that museums should consider moving forward.

Key words: altars, conservation, documentation, ephemeral, installations, registration

\section{RÉSUMÉ}

\section{Défis et innovations du soin des collections pour les compositions d'autel éphémères.}

Cette contribution examine des compositions d'autel (inter-)actifs au musée, du point de vue sous-examiné du soin des collections. Basé sur des recherches effectuées au Fowler Museum at UCLA, cet article étudie les détails de la construction, de la maintenance, la documentation et la conservation des autels. Il examine l'utilisation novatrice des catégories d'inventaire pour faire face aux identités et fonctions fluides des éléments constitutifs des autels. Il propose ensuite une analyse comparative de la documentation créée par des professionnels de la conservation-restauration pour trois autels entiers - dont l'un est une œuvre d'art contemporain - dans l'exposition Mami Wata: Arts pour les esprits de l'eau en Afrique et ses diasporas. Cette étude révèle les défis que présente l'exposition des compositions d'autel éphémères, fournit des exemples d'innovations muséologiques permettant de relever ces défis, et met en évidence les vulnérabilités de telles innovations que les musées devraient envisager pour aller de l'avant.

Mots clés : autels, conservation, documentation, éphémère, installations, régie des œuvres

\section{*}

\section{Introduction}

Once considered only as sites where religious material is displayed out of its original worship context (Bret, 20I3; Rajguru, 20I2), museums are increasingly becoming sites of active devotional engagement. The museum no longer only presents the sacred, but often constructs it in the form of active and interactive 
altars and shrines. But just as no two spiritual traditions are identical, the many manifestations of such traditions in museums present a variety of challenges to caring for these enigmatic assemblages.

A number of scholars have written about altars in museums, the history of this museological tradition, and its theoretical and political implications (Martin, 2003; Paine, 2013; Roberts, 1994a); but little research has been done on the finer details of practical management for constructing, maintaining, documenting and conserving altars. This paper addresses such concerns by looking at the collections care practices surrounding altar and shrine assemblages developed for exhibition at the Fowler Museum at UCLA.

The scope of this article is intentionally limited to investigating the practical work necessary for exhibiting altars that is carried out daily by museum professionals such as registrars, collections managers, installation specialists, and conservators. The purpose here is not to discuss from a curatorial perspective the politics of exhibiting living religious material culture (although discussion of such vital issues should always accompany the development of exhibitions that feature altars); but to delve into the lived experience of altars in the museum and explore how past and present practices can inform the development of future museological protocol ${ }^{2}$.

In the first part of this article, registration categorisation procedures are examined for what they reveal about complex altar ensembles and the fluid and fragmentary status, identities, and functions of their constituent parts. The ambiguity surrounding altar materials that do not have accessioned permanent collection status demonstrates both the need for innovation in preserving these "TR-numbers," "Props" and "Offerings," as they are called by Fowler staff, and the potential for confusion that such methods engender.

The second section regards documentation and preservation not of altar components, but of entire ephemeral, multi-partite altar assemblages. An examination of the archival traces of three disparate altars - one of which was also a contemporary artwork - installed for the Fowler's 2008 exhibition Mami Wata: Arts for Water Spirits in Africa and Its Diasporas takes a comparative look at the two micro-archives produced by conservation and curatorial staff, respectively. The registration and documentation practices for these complex altar collectives reveal how assumptions and expectations about the ontological identity of these entities, and about the purpose of documenting them, shape the content and structure of archives - often excluding immaterial, emotional, or spiritual information.

\footnotetext{
I. My use of the terms altar and shrine in this article do not follow an official definition. They are used loosely and often interchangeably, denoting any physical assemblage that embodies or represents a site of focussed spiritual activity.

2. For discussions relating to the ethics and politics of exhibiting religious material culture, consult Minucciani, 2013; Paine, 2000, 2013; and Sullivan, 2015.
} 
By examining the Fowler's collections care practices for past altars, this study reveals challenges of exhibiting ephemeral altar assemblages, provides examples of museological innovation to meet these challenges, and highlights the vulnerabilities of such innovations that museums should consider moving forward.

\section{Studying altars at the Fowler Museum}

The Fowler Museum at UCLA is a museum of "global arts and cultures with an emphasis on works from Africa, Asia, the Pacific, and the Americas-past and present." Operating in the space between the labels 'art' and 'anthropology' and flouting the restrictions these terms imply, the Fowler "consistently maintain[s] an extremely open attitude toward collecting examples of the boundless creativity of humanity," (Berns, Hamilton, Polk, \& Teeter, 20I4, p. I4). The design of their exhibitions is as unbounded as the content, and for over twenty years the Fowler has produced altar or shrine-like elements in conjunction with communities of believers and spiritual practitioners. These altars and shrines provide context to exhibitions that engage with diverse spiritual traditions from around the globe to illustrate the dynamic spiritual economy and aesthetics of those traditions' material worlds (Karp \& Kratz, 2015; Roberts, 1994b, 2008, 2017).

The lives these altars lived in the museum were just as diverse as the cultural traditions from which they were born; from Haitian Vodou to shamanic traditions of Vietnam and Southern China. In some cases, such as the 1995 exhibition Sacred Arts of Haitian Vodou, the museum purchased three altar assemblages from Haiti in their entirety, to highlight the artistry and faith of devotees (Cosentino, 1995). For the 2004 exhibition Botánica Los Angeles, a number of local spiritual practitioners personally installed their home altars at the Fowler with extensive control over curatorial communication and display, including the ability to select objects from the museum's permanent collection to integrate into their altar while it was on exhibition (Polk, 2004). Alternatively, when it was not feasible or desirable to transfer or build active altars into the museum, Fowler staff members have created non-working altar tableaux to provide a visual understanding of how a community of worship expresses their faith materially. Some altars have provoked the deposition of unsolicited visitor offerings, while others remained shielded from intervention by preventive boundaries. Although all of these altars represented sacred or spiritual devotion, many were also contemporary artworks by practicing artists.

Despite their significant differences, all of these exhibitions have been characterised by an intensive collaboration with spiritual practitioners from these traditions, and a commitment to providing depth, nuance, and context to religious art and communicating how it matters to those who make and use it. Another commonality was the need to translate devotional expression

I. The Fowler's working philosophy entails frequent collaboration and consultation with indigenous 
from its original forms to versions that mitigate potential risks and conform to museological standards. The placement of offerings such as food, drink, or plants, and the burning of candles or incense were substituted with conservation-approved materials like plastic fruit and flowers and electric candles. Such materials gathered by the Fowler, along with other materials used to construct altars like mass-produced Saint statues, now occupy a unique status in the museum as non-accessioned objects. These materials are currently referred to by Fowler staff as "TR objects" or "Props"; and although they can be considered to have a relatively low monetary or cultural value compared to the permanent collection, they are indispensable objects without which the altars in the museum would not be possible at all.

For this research, an ethnographic study was conducted at the Fowler Museum from the position of an intern with the conservation department from February to August 2017. This allowed for an analysis of the Fowler's visual-textual archives as well as their material archives (objects from past altars and their present-day storage circumstances). Formal and informal interview opportunities and participant observation also gave access to what can be called the Fowler's 'ritual archives': "the conglomeration of words as well as texts, ideas, symbols, shrines, images, performances, and indeed objects" that document and speak to certain cultural and religious experiences and practices (Falola, 2017, p. 703).

\section{Altar components: TRs, Props, and Offerings}

When asked about the process of installing altars, Fowler staff members invariably began by speaking about the "TRs" or "Props" required to convincingly translate these assemblages for the museum. It was explained that "Props" are materials acquired to give life to an altar tableau, but which do not require the professional attention of registrars, collections managers, or conservators, and are thus not assigned any identification number. In contrast, "TR" refers to the prefix of an ID number given to a non-accessioned object that may require collections care activities facilitated by a trackable registration number. Parallel to these are "Offerings": objects left on altars by visitors that similarly challenge traditional collections categories. The identity and value of these three types of objects are not absolute measures, but are relative, subjective, mutable, and negotiated, and they form a population of objects inside the museum - but outside the permanent collection - whose status and function are constantly in flux.

\section{Original and adapted uses of the TR category}

community representatives, spiritual practitioners, and living artists. They have invested deeply in NAGPRA repatriation activities, the co-production of exhibits, access to the permanent collection for ritual use, and community-led conservation projects such as the Maori feather cloak initiative carried out by a panel of indigenous scholars, weavers, and conservators (https://www.fowler.ucla. edu/exhibitions/fowler-at-fifty-maori-cloaks-maori-voices/). 
TR is one of the three number prefixes currently assigned by the Fowler when materials enter the museum. Loans are designated with an L-number, and arrivals that have been definitively purchased or gifted enter the permanent collection directly with an X-number. The Director of Registration and Collections Management (DRCM) explained that the TR, "Temporary Receipt" number, is assigned to objects when "their status is unknown." This includes "things that haven't been formally gifted yet, [or that] need to be looked at by the acquisitions committee before they get X'd [accessioned]".

Readers who are familiar with acquisition processes will recognise the use of temporary numbers and "Temporary Custody Receipts". The PastPerfect Museum Software provides a description for database users of the intended purpose for their Temporary Custody feature:

When items come into your museum, you may not wish to accession them right away [...] [They] may be held for consideration in a state of temporary custody. This allows your institution to analyze the proposed collection items to determine if they conform to your mission statement and can be cared for properly by your institution. (Witt, Whitfield, \& Stepansky, 2012, p. 57)

Clearly, the use of TR numbers is common practice in collecting institutions and is not greatly noteworthy in and of itself. My study underscores where the Fowler's practices diverge from standard procedures. Although the Fowler does assign TR-numbers to objects ultimately destined for the permanent collection, they are more closely associated with non-collection items used for exhibitions regardless of intent to accession. After exhibition, some of these TRs may indeed be promoted to X-numbers; but although the materials necessary to build altars may well 'conform to their mission statement' of showcasing the artistry of living cultural traditions, their commonplace origins and the difficulty to maintain, store, and track them often preclude accession.

PastPerfect advises that, after evaluating whether objects suit the museum's mission and can be appropriately housed,

The next step depends on whether the museum decides to accession the items held in Temporary Custody, keep them as a long term loan, or return or dispose of them. (Witt et al., 2012, p. 62)

\footnotetext{
I. All quotes of the DRCM from personal communication, 2017-03-06

2. Such as those used at Yale University's Peabody Museum of Natural History:

http://collections.paleo.amnh.org/assets/ypm_temporary_custory_receipt_form.pdf
} 
This protocol dictates that all TRs must become Xs or Ls, or else leave the museum entirely. There is no official option listed to retain them as non-accessioned materials and make use of them for exhibitions in alternative ways - however, this is exactly how the Fowler has adapted this category to contend with altar materials. The TR prefix was intended for objects suspended between non-collections and collections status; but the indeterminacy inherent to this liminal category has been co-opted as a way to meet the challenge of creating ephemeral altar installations that require a more flexible collections care protocol. This innovative adaptation of registration practice provides that flexibility; but flexibility often entails uncertainty.

\section{The Prop Storage}

The fluid identities of altar materials have led to some confusion about how to define the categories of Props, TRs, and Offerings. At the beginning of this research, most staff members did not know the origin of the TR-prefix or what the letters stood for; and, strikingly, the terms TR and Prop were often used interchangeably. Although they do not occupy the same category as unnumbered Props, the vast majority of TRs are held in the Fowler's "Prop Storage." Located next door to the main museum building, it is co-managed by both Exhibitions and Collections. Past rows of plinths, Plexiglas, mounts, and $\mathrm{AV}$ equipment, there is a large shelving unit full of cardboard boxes and clear plastic bags of colourful plastic fruit. The boxes are labelled with phrases like: PROPS, PROPS SAINTS, PROPS SAINT SIMONE SAINT FRANCIS CHROMOLITHOGRAPHS; and some even list their contents: "Box 43: 5 candles ( 2 red I wht. I purpl), 2 plastic skulls, 4 perfume bottles, I Box cigarillos, I bag of change."

This "bag of change" refers to coins deposited on past altars. Visitor offerings have never been explicitly solicited by the museum - although they have been welcomed - and the fate of visitor offerings were decided on a case-by-case basis. In some instances, money was donated to charity, and in others it was gathered for safekeeping amongst altar materials in Prop Storage. Thus, although the Prop Storage holds items of low significance such as plastic pineapples, it also preserves objects transformed into sacred offerings through the act of deposition. Such paradoxical heterogeneity is the leading characteristic of the non-accessioned collection in this storage facility: mundane yet sacred, cheap yet priceless.

A list kept by Collections Management of materials in Prop Storage revealed a mix of TR-numbered objects - "plaster saint figures, a Buddha, an iron cauldron, hats, enamel dishes" - and unnumbered props - "2 ceramic hands, 3 rubber snakes, plaster Jesus, book of dreams, bag of charms, 2 potted aloe vera, I bowl of spaghetti, I danish pastry, elegba gourds, Neon sign (Palm reader), Io drinking glasses..." and the list goes on. The fact that both TRs and Props are stored in the same location and used in similar ways may have contributed to the hazy taxonomy of these categories: 
Props are... see, this is where it gets confusing. [...] I'm not sure that plastic flowers ever got TR'd, they were just prop all the way, no question. Things like saint figures might have gotten a TR number as traveling with an exhibition, came back here, we decided we didn't want to keep it as part of the permanent collection, [and it] would have been transferred to Prop Storage. (DRCM)

\section{Defining TRs}

The above quote illustrates how, although the identity of some 'Props' like plastic flowers seemed clear and straightforward, no one felt able to precisely and conclusively define TR-objects. It was often said that they are "not real objects," or with an alternate emphasis, "not actual objects." Although the inferred meaning is that TRs aren't accessioned collection objects, the vocabulary used is truly arresting. If plaster saints, fake skulls, and chromolithographs aren't real objects - what are they? This ambiguity and the vernacular elision of TR-numbers with non-numbered Props indicates the inability of current museological categories to encompass objects whose identities are unstable.

In conversations during recorded interviews and over shared daily tasks, it became clear that TRs were understood in a variety of ways amongst museum staff. To the Conservator, a defining characteristic was that they are replaceable; one example of a type of object for which other examples can be readily procured. The Chief Curator saw TRs as functionally valuable, not physically valuable; significant not because of what they are, but what they do in the museum. The Curator of Latin American and Caribbean Popular Arts highlighted the relational identities of these objects in pointing out that "a skinny black candle only makes sense in a group together, in an altar context". This echoed the Registrar's view of TRs as accessories to other exhibition objects, and the Curator of Archaeology's understanding that they support an artistic or curatorial vision; when used collectively, they are able to set a scene and provide context in a way that singular accessioned objects cannot. Finally, the DRCM saw the TR category as a liminal space where items are "betwixt and between."

In all of these various conceptualisations, however, it is clearly understood that the material integrity of these items is not an obligation the museum must uphold as it does with the permanent collection. Whereas an X-numbered object would never be physically altered, a TR item could become an interactive exhibition element, wear out through handling, and disappear completely. In being unbound by rigorous collections policies, "there's a nimbleness to the TR" (DRCM) that has allowed a single plaster statue of a Catholic saint to become a commodity for sale on the shelves of a recreated Botánica shop, an

I. personal communication, 2017-03-23 
alter ego of a Haitian Vodou spirit, or a component of a contemporary artist's installation. These nimble items are defined by their relation to a greater whole, their identities a palimpsest of the functions they have performed and the spirits they have represented in many an altar. This range of exhibition possibilities at the Fowler would not have been possible had they not diverged from traditional "Temporary Receipt" procedures.

\section{Effects on collections care practice}

The use of the TR category for altar components has not always been standard practice at the Fowler. Archival and database research revealed that there have been a number of other configurations used in the past.

Altars exhibited in Sacred Arts of Haitian Vodou (1995) included Xs and Ls; but instead of TRs, there were P-numbers, a designation that was unknown to or forgotten by Fowler staff at the time of this study. The prefix likely stands for "Prop," given the 'VODOU.PROPS' Activity ID listed in the database. Interestingly, P-objects included not only altar objects, but also exhibition hardware: speakers, mounts, wall panels. Thus, the supporting objects within the altar and the supporting objects around the altar shared the same status at that point in time.

The Registrar also recalled seeing older altar materials in storage displaying A-numbers, although the origins of this category too are lost to institutional memory. The "A" likely stands for "Accessory" - a term that is much more prescriptive of a particular identity and status than the open-ended use of the TR category.

The evolution of these classifications demonstrates how the Fowler has for decades attempted to configure collections care practice to changing exhibition techniques. When an ID-number is needed to track an altar component, the TR now performs this function, allowing staff to determine the necessary level of attention without imposing unnecessary obligations. The DRCM sees the TR status as an indication to Fowler staff that this object does not require formal condition reporting for each new venue; and although minor condition issues may be treated, no lengthy treatment reports are necessary. In short, "the restrictions upon you are diminished."

While conservators have a responsibility to ensure the material stability of all objects in an exhibition, their work is organised around indications of priority and hierarchy inherent to object ID numbers. Theoretically, if the TR category was stable and easily defined, TRs would always receive lesser treatment and documentation efforts from the Fowler's Conservator; but in practice, it is not so straightforward:

I can't quite understand why something's a TR and why it isn't. For some of our Haitian altars, we have tons of material that was 
really good that was TR'd; but to me, it looked exactly the same as something that was [X'd]. If I'm thinking about [conservation] as the materials... those materials are exactly the same as the materials of the accessioned piece; so I'm going to treat them exactly the same.

(Personal communication, 2017-03-06)

The conservator's own professional ethics thus supersedes the institutional label of TR or Prop and warrants a higher level of attention even for objects with a lower value designation. By the same token, objects that had once been given a TR number, but which would now remain unnumbered (e.g. plastic pineapples), he may treat as props. It is important to stress again that no obligations to TR objects are broken when this happens - there is no legal or professional obligation to Props or TRs that require them to be tracked, stored, and documented in certain ways. The conservator may treat TRs as if they were Xs or Props, but in either case they may not be thoroughly documented. This is the great compromise of the malleable TR category that offers museum staff a liminal space in which to manoeuvre with careful deliberation on a case-by-case basis: there may be no records of these practices left behind. What makes it productive also makes it vulnerable.

The same issues of categorisation and documentation presented above for altar components are relevant for entire altar assemblages. The next section examines the construction and recording of three altars from one exhibition.

\section{Altar assemblages: three Mami Wata altars}

The 2008 exhibit Mami Wata: Arts for Water Spirits in Africa and Its Diasporas examined the figure of Mami Wata, a seductive and dangerous but also protective and generous spirit with roots in west and central Africa and incarnations in the Caribbean, Brazil, and the US (Drewal, 20o8). Her portrayals are shaped by African water spirits, European mermaids, Hindu goddesses, and Christian and Muslim Saints. The exhibition traced cultural flows and currents feeding into Mami's incarnations as half-woman half-fish or snake charmer. Three altars demonstrated her at work in people's lives today.

The person responsible for their realisation as exhibition elements was the Fowler's Curatorial and Research Associate (CRA), who recounted the rich, storied histories behind these altars - each fundamentally different from the other, and each with a different role provided by the CRA in bringing it to fruition:

[The curator] wanted three altars. One was from Mamissi Pascaline, a Mami Wata practitioner in Benin. She had a specific altar and [he] wanted us to purchase it, bring it to the United States and recreate 
it here in our gallery. The second altar was from the Dominican Republic, dedicated to Santa Marta la Dominadora Lan incarnation of Mami Wata whol lifts up women deprived of their dignity and dreams for the future [...] And the third altar was by contemporary artist Eve Sandler. She created this very special altar/dedication in memory of her ancestors who came as slaves to North Carolina. ${ }^{1}$

\section{9}

The CRA also introduced the complex issue of classification by outlining the variations in these assemblages' ontological identity:

Just to sum it up for you quickly, the first one from Benin was a simile; a reproduction of an existing altar. The second one [...] was going to be a reproduction of an altar in the Dominican Republic, but at one point -- it unleashed its power. It got beyond that and it became a true altar [...] And then the third one had the spirit of the ancestors, and the artist herself dedicated the altar.

While many Fowler altars have had TR-numbers assigned to individual objects contained therein, the Benin and Santa Marta altars were categorised as holistic entities, and each assemblage entered the database with a single "TR" registration number. Because of the diminished restrictions on documenting TRs, the database entries for these altars give the impression that they had similar identities and construction methods; but as we will see, this is not the case.

\section{The Benin Altar}

This altar was purchased according to the desire of Mami Wata priestess Mamissi Pascaline. She actively sought to replace materials in her home altar as a natural function of upkeep and care, which was made possible with the funds from the sale of her obsolete altar components to the museum. The CRA described the Benin altar's installation as "quite simple, because all I had to do was follow images." Although most of the assemblage was acquired directly from the practitioner, some items like cloth, shells, and a small guitar were bought in Los Angeles - or scavenged, like the plate sourced from the Fowler's own staff kitchen.

Despite the disparate origins of its components, this altar represented Mamissi Pascaline's devotional practice. It was not meant to function as an altar, but to visually contextualise Mami Wata's role in West African coastal communities.

I. All quotes of the CRA from personal communication 2017-08-07 
The CRA's task was simply to ensure aesthetic accuracy. Her role in the Santa Marta altar was radically different.

\section{The Santa Marta Altar}

A syncretic spirit, Santa Marta is both a lwa spirit of Dominican vodú and a folk Catholic Saint. The Fowler's altar was based on an active community altar in the Dominican Republic that could not be transferred to Los Angeles. In contrast to the Benin altar whose creator no longer wanted to use those particular materials, the Dominican Santa Marta altar still had an active life in its community and the materials remained in use. Because of this, a new altar assemblage was created for the Mami Wata exhibition by the Fowler's CRA, who herself ultimately became devoted to the Saint.

In this endeavor, she was supported by an informant of the exhibition's curator who lived in the Dominican Republic and actively worshipped with the priestess at the original shrine's location. The CRA began by reproducing photos sent by this informant, but "got fascinated by this woman, this Saint who empowers women" and "got fully involved." She spent months developing the altar in her workspace, collecting items that please Santa Marta - alcohol and perfume bottles, cigarettes, crucifixes, incense, and (plastic) fruit and cakes ${ }^{1}$.

Before the vernissage, she and the curator's informant inspected the result:

[We] were looking at the altar, and then we looked at each other and said, "how about if we consecrate the altar?» Just like that, at the spur of the moment.

They knelt and said the Lord's Prayer in Latin and Armenian respectively "and at the end we were both crying ... that's when it became real. That's when it accepted our prayers". This dedication recurred at subsequent exhibit venues, a new staff member in front of the altar with the CRA spontaneously consecrating it with a prayer; and "so it became live."

Based on exhibition reviews and the appearance of offerings, it seems that visitors could sense that this was an active altar. After seeing the exhibit at the Smithsonian's National Museum of African Art, New York Times art critic Holland Cotter called the Santa Marta altar

an imposing one, thick with candles, coins, shells, plastic flowers and mass-produced holy cards [...] Forty years ago such material would

I. For audio of a panel discussion on the exhibit, see: https://www.fowler.ucla.edu/exhibitions/ mami-wata/ 
never have been admitted to an art museum. But here it is: abundant, alive, interactive. (Cotter, 2009)

The CRA recalled that offerings were left on Santa Marta's altar, which she anticipated upon its consecration at the Fowler. When she and the informant began crying, she told the guards, "if anyone wants to approach the altar and touch anything and place anything, don't refuse. Absolutely allow it to happen."

Indeed, a dish of coins she placed on the altar was supplemented by coins from visitors, along with other offerings: Saint medals, candy, bracelets, combs, and even written letters and requests. The CRA "got them all back" and they were deposited "along with all the ephemeral objects" in Prop Storage. She saw visitor offerings as a positive outcome that "added to the life" and the "spirit of the altar,"

because they carried the beliefs of people and were added to the altar. An altar is a compilation of faith, belief, hope for the future. Hope for the world. [...] How can we discard them? They are part of the altar.

99

She saw the altar as imbued with significant immaterial properties, as a composite entity encompassing objects left by visitors, and as evolving over time. The Benin altar, though no longer active, was understood to represent those same characteristics, if not currently embody them. The third altar was understood quite differently.

\section{Mami Wata Crossing, an "Altar-Installation" by Eve Sandler}

Eve Sandler's artwork Mami Wata Crossing included an old desk "as both an altar and reliquary": a memorial to relatives who endured the Middle Passage, and altar to her grandmother. The desk was crowned with a bowl containing a live betta fish symbolising Mami's realm, and inside the desk's open drawer were relics of her grandmother -perfume bottle, thimbles, crucifix - strewn amongst items associated with Mami Wata like tobacco, shells and sand.

The CRA's responsibilities for this "contemporary altar-installation," as the work was called in its database entry, were greatly reduced compared to the other altars. It was rather the then-Director of Conservation (DoC) who "handled" Mami Wata Crossing, overseeing installation, packing, and shipping - but not the betta fish element, which the CRA installed and monitored. The CRA

I. For a similar view see also (Roberts, 2008) 
said this shift in professional roles and responsibilities was because Mami Wata Crossing was a loan while the first two assemblages were TR numbers; but its identity as an artwork may have been a more influential factor.

Worried that visitors might approach Mami Wata Crossing after interacting with the Santa Marta altar, and "in that hopeful feeling" leave or take things, the CRA said

we made sure that this was treated as art work [...] Just by having a security guard in the same room, just watching and saying : "please do not touch this altar'

While still called an "altar," its status as art prompted a transfer of practical handling duties from Curation to Conservation and alternative exhibition directives. The question then arises of whether these implicit ideologies are reflected in the archives.

\section{Documentation: Two Micro-Archives}

Each work that enters a museum yields "micro-archives," "constructed simultaneously, with each department maintaining its own appropriately focused record of specific aspects of the work" (Hölling, 2017, p. I43). The organisation and contents of two such micro-archives were investigated to understand what was highlighted and what remained invisible.

\section{Curation}

The CRA created a binder called "Photographic Documentation of the Altars in the MAMI WATA Exhibition" as an installation aid. For the Benin and Santa Marta altars, step-by-step images show the assembly process including the placement of each item, labelled with a Roman numeral. Besides a packing list from Collections, these roman numerals are the only written material included for these altars.

This lack of text is a function of the CRA's goal for documentation - to efficiently guide the installation process - which she felt was best achieved with photos. In fact, even the scant roman numeral labelling text was nullified, as it became "more complicated than the actual installation following visual guidelines." The numbering system was thus suspended in favour of a more "easily attainable" visual guide allowing these "transient, ephemeral constructions" to evolve over time in contrast to "a work of art that should be preserved as it is."

Eve Sandler's installation, of course, was a work of art - even as it was an "altar and reliquary." Although this work was "handled" by the DoC, Mami Wata Crossing is still present in the CRA's altar records; but only the betta fish element 
for which she was responsible. This shows how this archival source was shaped by its purpose: aiding the CRA in her reinstallation duties. Consequently, this single documentation source only paints a partial portrait of the altars' lives. A wider - but still incomplete - view of their history is presented in the micro-archive created by the Fowler's DoC.

\section{Conservation}

While the Curatorial altar archive is concentrated in one binder, altar records are found in three of Conservation's eleven Mami Wata binders: one exhibition overview, one just for altars, and nine with condition reports for all works in order of Exhibition Number.

These are more detailed and comprehensive than the curatorial archive, reflecting a different professional role and aim: describe each work in minute detail to account for any physical change. This resulted in a larger micro-archive with documents evincing evolutions in opinion and practice, such as changing registration number subdivisions - similar deliberations to those of how to categorise altar components discussed above.

Another window on the evolving conception of altars is in the documentation structure itself, which can be considered as the visible representation of the material classifications carried out in the museum (Beltrame \& Jungen, 20I3, p. 75I). The binder that originally read "Fowler Cons Dept MWata CR Binder for 3 "Altars" had its 3 crossed out and replaced by a 2. The Benin and Santa Marta altars were inside, but Sandler's work had been re-filed with the other condition reports. The decisions behind such changes are often made in conversation or on-site in exhibition spaces, requiring extra time and effort to document these exchanges. If this does not happen, significant biographical moments may be lost, leaving unanswered questions; but even the smallest piece of information in the archive may provide answers.

Though an email included in these records shows the DoC referring to her "3 Mami Wata altars" binder just one day prior, a handwritten note made while speaking to the CRA reads:

\section{Terminology}

- Eve Sandler's installation (= artwork)

- Benin altar

- Domin. Repub. altar

This small note - with the line about Sandler's piece highlighted - is a clarification on the fundamental nature of these three works, drawing a line between Sandler's altar and the other two; and it likely explains the documentation's restructuring. 
Many such details were found in conservation binders, but not everything absent from the curatorial micro-archive is included in that of conservation. When cross-referenced with the CRA's oral account, we see how crucial immaterial elements of the altars' life cycles were recorded only in the ritual archives of institutional memory.

Neither the curatorial nor conservation documentation tells of altar consecrations, offerings left by visitors, the source of each altar component, or their subsequent storage locations. As non-collection materials, there is no ethical obligation to record this information in collection management systems; but nor indeed would those systems accommodate such unconventional object biographies. Because they fell outside the scope and purpose of both micro-archives, these events only live on in institutional memory that will disappear as staff leave the museum; unless it is recorded through observations and interviews such as those carried out for this research.

\section{Possibilities for the future}

Some possible solutions to the pitfalls of traditional registration systems and documentation methods presented in this article may be found by adapting collections management systems and museum workflows.

New versions of museum database software should begin to take in to account the ephemeral nature of composite works like altars - as well as complex contemporary artworks like installations or performance art that similarly include assemblages of material and conceptual elements which evolve over time. Some such efforts have already been undertaken, as in the 2018 version of Gallery Systems' TMS (The Museum System) with the addition of features like the 'Events' module that provides an opportunity to link relevant experiences and incidents to an artwork. In the case of altars, an event entry could be created to record a consecration or the deposition of offerings. Another useful new feature of TMS is the ability to create 'Virtual Objects,' which may be of use for altar components that are not given X, L, or even TR numbers, or for creating an entry to signify an entire altar assemblage that includes multiple numbered and unnumbered objects. For institutions who do not use collections management systems with built-in features like this, current databases should be examined for creative ways to include immaterial and experiential aspects of a work's life.

New workflows can also be developed to institute standard practices that capture institutional memory. Given that the 'dissociation' of collections objects from relevant information about them is considered one of the 'Ten Agents of Deterioration' in the field of Preventive Conservation', the potential loss of

I. See the American Institute of Conservation's wiki entry for "Ten Agents of Deterioration" (https://www.conservation-wiki.com/wiki/Ten_Agents_of_Deterioration) and the Canadian Conservation Institute's webpage on the Ten Agents of Deterioration (https:// 
knowledge about altars uncovered in this study is not an uncommon phenomenon in museums. To address the extreme vulnerability inherent in ephemeral assemblages, museums might consider adopting a 'Reflexive Institutional Ethnography' approach to collections care by recording internal staff interviews, altering documentation forms, and critically examining current protocol to identify and record important museological practices at risk of disappearing irrevocably with staff changeover and the passage of time (NACCA Doctoral Researchers, 2018).

These are just a few initial suggestions of possible advances in museological practice for the improved collections care of ephemeral assemblages; whether they be altars or works of contemporary art. The author hopes that the overview of challenges faced and innovations developed by the Fowler Museum at UCLA presented in this article will prompt further study of how museological enquiry can address the emerging needs of interactive exhibition formulas.

\section{Conclusion}

The diversity of identities among ephemeral altar assemblages presents both vulnerabilities and opportunities for museology. If collections care staff attempt to fit ephemeral objects into existing documentary structures designed for singular material artworks, this hides rather than highlights their complex immaterial nature. At the Fowler Museum, these diverging ontologies have instead prompted fluid documentary responses that adapt to each object on a case-by-case basis, such as the innovative use of the TR category, or the CRA's decision to privilege visual over textual documents to reflect the less rigid parameters required of altar installations.

While a degree of fluidity is necessary for the Fowler to be able to continue producing their signature altar and shrine elements, it would be a disservice to their innovative work and to the relational complexity of these assemblages if only material facets of these composite works remain in the archives. I do not make a case here for documenting every detail of every consecration, for example. Such observances might contain secret or privileged knowledge that should not be recorded in museum archives; but it can only be beneficial for the altar assemblage, and for those who performed such an act, to record the fact that something did in fact occur.

Altars are the intersection of faith, belief, hopes, and fears with spiritual beings and the objects that symbolise them, please them, or supplicate them. The Benin and Santa Marta altars were understood to be different from, and so did not receive the same documentational treatment as the Mami Wata Crossing altar-installation - an artwork, and thus an item which conformed to existing documentation methods. But in recognising the non-conformity of altars and their components to categories of more easily documentable materials, the very

www.canada.ca/en/conservation-institute/services/agents-deterioration.html) 
facets that set them apart are at risk of being lost. The devotional histories, consecrations or dedications, and visitor offerings that represent the 'liveness' of these altars remain vibrant memories for those who experienced them; but such crucial biographical moments in the lives of altars (or any other complex and relational artwork) are in danger of being lost for good if no museological practices are in place to perceive them.

\section{ACKNOWLEDGEMENTS}

This study was undertaken as part of a PhD with the research consortium NACCA (New Approaches in the Conservation of Contemporary Art). It has received funding from the European Union's Horizon 2020 research and innovation programme under the Marie Skłodouska-Curie grant agreement No 642892. The author wishes to acknouledge the guidance of her phenomenal supervisors - Carolina Orsini, Iolanda Ratti, and Renée Van de Vall - and advisors - Christian de Brer and Ellen Pearlstein - as well as the generous participation of the staff at the Fouler Museum. I am particularly grateful to Gassia Armenian, Terri Geis, Jo Hill, Izzy Kelly-Ramirez, Patrick Polk, Rachel Raynor, Matthew Robb, Jeanette Saunders, and Wendy Teeter for their exceptional contributions.

\section{References}

Beltrame, T. N., \& Jungen, C. (2013). Cataloguer, indexer, encoder. Ou comment les données prennent vie. Revue d'anthropologie Des Connaissances, 7 (4), 747-759. https://doi.org/10.3917/rac.021.0747

Berns, M., Hamilton, R. W., Polk, P. A., \& Teeter, W. (20I4). World arts, local lives : the collections of the Fowler Museum at UCLA. Los Angeles: Fowler Museum at UCLA.

Bret, L. (2013). De l'objet rituel à l'œuvre vodou. Le musée comme espace de transformation du sacré. Religions \& Histoire, 10, 58 -59.

Cosentino, D. (Ed.). (1995). Sacred Arts of Haitian Vodou. Los Angeles: UCLA Fowler Museum of Cultural History.

Cotter, H. (2009, April 2). From the Deep, a Diva With Many Faces. The New York Times. Retrieved from http://www.nytimes.com/2009/04/o3/arts/ design/ozwata.html

Drewal, H. J. (2008). Mami Wata: Arts for Water Spirits in Africa and Its Diasporas. Los Angeles: Fowler Museum at UCLA. 
Falola, T. (20I7). Ritual Archives. In A. Afolayan \& T. Falola (Eds.), The Palgrave Handbook of African Philosophy (pp. 703-728). Palgrave Macmillan. https://doi.org/IO.I057/978-I-I37-5929I-O_45

Hölling, H. (20I7). Paik's Virtual Archive: Time, Change, and Materiality in Media Art. Oakland: University of California Press.

Karp, I., \& Kratz, C. A. (2015). The Interrogative Museum. In R. Silverman (Ed.), Museum as Process: Translating Local and Global Knowledges (pp. 279-298). New York: Routledge. Retrieved from http://halleinstitute.emory.edu/ karp/articles/museums_exhibitions/2015_interrogative_museum.pdf

Martin, J.-H. (2003). The World's Altars and the Contemporary Art Museum. Museum International, $55(2), 38-45$.

Minucciani, V. (Ed.). (2013). Religion and Museums. Immaterial and Material Heritage. Torino: Umberto Allemandi \& C. Retrieved from https://www. allemandi.com/libripdf/ReligionandMuseums.pdf

NACCA Doctoral Researchers: Wielocha, A., Quabeck, N., Miller, Z., Spangler-Bickell, C., Barok, D., Castriota, B., ... de Haan, P. (2018, November 15). Beyond the Artist Interview: Notes from the Field. Presented at SBMK (Dutch Foundation for the Conservation of Contemporary Art) Summit on (Inter)National Collaboration: Acting in Contemporary Art Conservation. https://doi.org/I0.21942/uva.8150621. Retrieved from https://figshare. com/account/projects/2II55/articles/8I5062I

Paine, C. (Ed.). (200o). Godly Things: Museums, Objects and Religion. London and New York: Leicester University Press.

Paine, C. (2013). Religious Objects in Museums: Private Lives and Public Duties. London and New York: Bloomsbury.

Polk, P. A. (2004). Botanica Los Angeles. Los Angeles: UCLA Fowler Museum of Cultural History.

Rajguru, M. (20I2). From Shrine to Plinth: Illuminating the Identity of the Hindy Deity in the Museum Through Artistic Intervention. Journal of Museum Ethnography, (24), IIO-I28. Retrieved from http://www.jstor. org/stable/4I7IO458

Roberts, M. N. (1994a). Does an Object have a Life? In M. N. Roberts, S. Vogel, \& C. Muller (Eds.), Exhibition-ism: Museums and African Art (pp. 37-55). New York: The Museum for African Art.

Roberts, M. N. (1994b). Exhibition-ism: Museums and African Art. In M. N. Roberts, S. Vogel \& C. Muller (Eds.), Exhibition-ism: Museums and African Art (pp. 22-35). New York: The Museum for African Art.

Roberts, M. N. (2008). Exhibiting Episteme: African Art Exhibitions as Objects of Knowledge. In K. Yoshida \& John Mack (Eds.), Preserving the Cultural 
Heritage of Africa: Crisis or Renaissance? (pp. I70-I86). Oxford: James Currey and Unisa Press.

Roberts, M. N. (20I7). Altar as Museum, Museum as Altar: Ethnography, Devotion, and Display. In G. Buggeln, C. Paine, \& S. B. Plate (Eds.), Religion in Museums: Global and Multidisciplinary Perspectives (pp. 49-56). London / New York: Bloomsbury.

Sullivan, B. M. (Ed.). (2015). Sacred Objects in Secular Spaces. Exhibiting Asian Religions in Museums. New York: Bloomsbury Academic.

Witt, B. S., Whitfield, J. C., \& Stepansky, A. J. (20I2). Temporary custody. In PastPerfect 5.o User Guide (3 ${ }^{\text {rd }}$ ed., pp. 57-64). PastPerfect Software, Inc. Retrieved from http://museumsoftware.com/v5userguide.html 